\title{
Self-perceptions of Airbnb hosts' responsibility: A moral identity perspective
}

\begin{abstract}
Responsible host conduct has emerged as important in regulating the peerto-peer accommodation phenomenon. Utilising moral identity theory, this paper explores how hosts draw on their own perceptions of morality and responsibility to inform hosting practice. Through a qualitative research approach, the study reveals a variance of host practices that are not necessarily reflective of the perceived moral identity of hosts. In particular, the paper exposes the moral questions that hosts need to answer at different phases of the peer-to-peer transaction and, especially, if and how they enact certain aspects of their moral identity to guide their behaviour. The study offers a typology of Airbnb hosts' (im)moral behaviour, which may be of theoretical and practical value to academics and policymakers alike.
\end{abstract}

Keywords: moral identity; responsibility; host perceptions; Airbnb

\section{Introduction}

Peer-to-peer ( $\mathrm{P} 2 \mathrm{P})$ sharing activities have become popular within the accommodation sector, where online platforms enable individuals to easily convert their properties into short-term rentals (Belk, 2014). Whilst there are numerous P2P accommodation networks, Airbnb is recognised as one of the world's most successful (Volgger et al., 2019). Since 2008 when it was first established, Airbnb has expanded to include more than 200 million members in over 191 countries (Airbnb, 2018), warranting its title as "a global tour de force in the tourist fabric of numerous places" (Ioannides et al, 2018:2). The growth of Airbnb is unsurprising considering the several socioeconomic benefits it may provide to both hosts and guests (Ikkala and Lampinen, 2015). For instance, it has been suggested to offer a more authentic tourist experience (Bucher et al., 2018; Lalicic and Weismayer, 2017; Palauskaite et al., 2017; Mody et al., 2019; Shuqair et al., 2019) that facilitates 'a home away from home' feeling (Zhu et al., 2019). Similarly, it allows hosts to earn additional income by utilising idle property (Lutz and Newlands, 2018).

Nonetheless, the rapid growth of Airbnb has yielded concerns in relation to its effects on the hotel sector, local housing markets and local communities (Hadjibaba and Dolnicar, 2017; Mody et al., 2019; Stergiou and Farmaki, 2019). There is evidence of tourist overcrowding in central areas as a result of Airbnb growth, which has reportedly contributed to the touristification processes that transform urban space and, consequently, negatively impact the lives of residents (Farmaki et al., 2020; Ioannides et al., 2018). Much of the negative impacts of Airbnb have been attributed to the illegal operation of many Airbnb rentals (Gottlieb, 2013) and the management of multiple listings by 'professionals' such as real estate companies (Stergiou and Farmaki, 2019). For instance, studies report an increasing number of landlords who are evicting tenants in order to vacate units for use as short-term rentals (Stergiou and Farmaki, 2019). Similarly, many Airbnb hosts seem to operate Airbnb rentals illegally with their 'free rider' attitude being encouraged by the platform's absence of accommodation taxes (Guttentag, 2015). In addition, the absence of a regulatory framework in $\mathrm{P} 2 \mathrm{P}$ accommodation has fuelled concerns over the potential discriminatory behaviour of hosts (Cheng and Foley, 2018; Farmaki and Kladou, 2019) as well as unethical acts illustrating disclosure of information to guests (i.e. installing hidden cameras in rented properties). 
Consequently, calls for the strengthening of regulatory controls on Airbnb-type accommodation have intensified over the years (Edelman and Geradin, 2015; Gurran and Phibbs, 2017). In fact, anti-tourism marches are increasing in cities that are highly impacted by overtourism, to which Airbnb's growth contributes (Nieuwland and van Melik, 2018). Airbnb has been accused of reinforcing a nightmarish form of neo-liberalism that contributes to the creation of unregulated marketplaces (Martin, 2016) and the deception of customers by capturing and controlling user data (Srnicek , 2017), a phenomenon referred to as 'platform capitalism'. Even so, attempts to control the growth of Airbnb have insofar been largely unsuccessful due to the varying regulatory structures among cities (Grimmer et al., 2019) and the difficulty of regulating an online platform (Edelman and Geradin, 2015). According to Espinosa (2016), overlooking the innovative aspects of Airbnb and treating it as a traditional industry player limits the ability of formulating a feasible regulatory framework.

Within this context, the role of Airbnb in mitigating negative impacts by setting rules and ensuring users of the platform enforce them was highlighted (Cheng and Foyle, 2018). Equally, the responsible conduct of hosts as co-facilitators of P2P transactions has been emphasised (Farmaki and Kaniadakis, 2018). Airbnb hosts seem to emerge as a "community of practice" with the aim to share knowledge, experience and also set boundaries between what might be understood as responsible hosting behaviour (Farmaki and Kaniadakis, 2018). As such, hosts' perceptions of morality and responsibility become relevant. Nonetheless, it remains a challenging task to monitor the compliance of hosts to regulations (Nieuwland and van Melik, 2018). According to Sundararajan (2014), the concept of P2P sharing platforms may imply co-creation yet does not necessarily elicit a framework in which responsibility is equally shared. In this regard, it has been argued that individual regulation is better suited to govern Airbnb (Jonas, 2015). As Cohen and Sundararajan (2014) asserted, self-regulation may alleviate regulatory challenges that can otherwise impede the innovation elicited by the opportunities offered through P2P exchanges. Evidently, the responsible conduct of Airbnb hosts is key in the efforts to regulate the growing phenomenon.

Surprisingly, pertinent research has virtually ignored host views of their role in mitigating the impacts of Airbnb. Against this background, this paper explores the perceptions of Airbnb hosts with regard to their moral responsibility in P2P transactions. We draw from moral identity theory to understand how Airbnb hosts' views on moral responsibility are generated and how their hosting practice is linked to personal motivation to act responsibly. More precisely, we analyse how hosts draw on their own perceptions of morality and responsibility to inform their practice and how such perceptions compel them to use their role as co-facilitators of the P2P transaction in consistency with their moral values. In so doing, the study offers insights that contribute to policymaking and the efforts to improve platform governance, especially with regard to the negative impacts of Airbnb's expansion on local communities. As such, the study is timely in highlighting how business models based on sharing activities (i.e. P2P accommodation platforms) can contribute to more sustainable infrastructure in tourist places (Cohen and Munoz, 2016).

Overall, the study makes valuable contributions to both tourism and moral identity literatures. First, the concept of moral identity has been scarcely examined in tourism studies; a surprising omission considering calls for greater emphasis on morality in tourism scholarship (i.e. Caton, 2012). Second, by drawing from service provider perceptions, we contribute to existing knowledge on moral identity where focus was primarily placed on guest perspectives (i.e. He and Harris, 2014). In addition, the 
study advances both the conceptualisation and operationalisation of moral identity by considering the complexity of its content in the setting of $\mathrm{P} 2 \mathrm{P}$ accommodation that is underpinned by a commercial and social orientation. As such, the study contributes to management literature that has examined moral identity mostly in organisational settings and in relation to voluntary behaviours (e.g. Reed et al., 2007). Moreover, by focusing on both moral identity internationalisation and symbolisation, we contribute to moral identity research which has most often conducted empirical examinations of moral identity internationalisation (Mulder and Aquino, 2013). By examining Airbnb hosts' moral identity perceptions and how they are enacted in host practices along various stages of the $\mathrm{P} 2 \mathrm{P}$ exchange, a better understanding is gained of how moral identity evolves in a socially mediated process.

\section{Literature Review}

\subsection{Moral identity}

The term 'moral identity' has been defined as a "self-conception organised around a set of moral traits" (Aquino and Reed, 2002: 1424). In other words, if individuals feel that moral traits such as being altruistic, honest, friendly, caring, and fair are central for defining their sense of self, they have a strong moral identity. Thus, being a moral person may occupy different levels of centrality in peoples' self-identity (Reed, 2002). The strength of this association to the self is referred to as the "selfimportance of moral identity" (Reed and Aquino, 2003: 1272); if a person's moral identity has high importance to their self-definition then the readiness with which that moral self-schema will affect moral judgements and behaviours is high and vice-versa (Hardy et al., 2010). As Damon and Hart (1992) have aptly put it, people whose selfconcept is organised around their moral beliefs are more likely to turn those beliefs into action.

Evidently, it is the enduring association between an individual's self-concept and the mental representation of their moral character that links this construct to moral behaviours. Moral identity, therefore, emerges as an important source of moral functioning leading to greater congruence between one's moral principles and behaviours (Hardy et al., 2010). Given that the centrality of moral identity varies across individuals, it follows that individuals with a strong moral self-concept should be more likely to expend efforts to self-regulate their behaviour (Seeley and Gardner, 2003). As Power and Khmelkov (1998) argue, the relationship between a person's conception of their moral self and their behaviour is related to the need to maintain a consistent self-image associated with this moral self-schema. In a similar vein, Blasi (1993) states that moral action stems from the desire to act in ways that are consistent with one's ideals.

The above conceptualisation of moral identity corresponds to Erikson's (1964) proposition than an identity comprises of two dominant characteristics: first, identity is rooted in the core of one's being and second it involves being true to oneself in action (Erikson, 1964). Accordingly, Aquino and Reed (2002) theorised that moral identity has a private and a public aspect labelled, respectively, as internalisation and symbolisation. Internalisation reflects the degree to which moral traits are central to the overall self-schema. Symbolisation reflects the degree to which these traits are manifested outwardly to others. Aquino and Reed (2002) proposed that people with a strong moral identity should strive to maintain consistency between conceptions of their moral self and their actions. However, situational and contextual cues may 
activate or suppress knowledge structures, including the moral self-conception, influencing the social information processing which is pertinent to moral behaviour.

\subsection{From moral identity to moral responsibility in P2P accommodation}

It is not adequate to decide what is morally good in a given situation; rather, individuals need to make decisions with regard to what moral good is required for their self (Walker, 2014). On this view, judgements of responsibility are the result of the integration of morality in one's sense of self, which extend moral identity to concrete action (Blasi, 1993). Moral responsibility, therefore, emerges as an attitudinal dynamic arising from within the self that directs one's concern to being responsive to the interests and needs of others (Wineberg, 2006). Accountability implies that a person answers for his/her actions rather than being merely held responsible for something. As such, accountability has been acknowledged as a mechanism through which societies may control the behaviour of their members (Beu and Buckley, 2001) such as through the imposition of penalties in the case of illegal or irresponsible activities. Even so, the concept does not necessarily reflect the intentions behind a specific action. Contrary, moral responsibility recognises that moral values are central to one's self, guiding his/her behaviour as one feels ethically responsible to other parties.

Generally, responsibility may be undertaken on an individual or collective level. Individual responsibility occurs when people actively take responsibility rather than passively being responsible (Linley and Matlby, 2009). Collective responsibility is concerned with people's collective accountability. Nonetheless, collective responsibility is difficult to establish (Kaufman, 2015), particularly when there is absence of a relevant legal framework. Within this context, the elements of attribution and diffusion of responsibility emerge. Specifically, people will assign responsibilities to themselves when there are no other social agents to take up moral responsibility or, alternatively, they will diffuse responsibilities to others, particularly when there are too many actors involved in an act and responsibility is not clearly assigned to individuals or its application is inhibited by external barriers (McGregor, 2017). Correspondingly, irresponsibility may be exhibited in people's conduct (Linley and Matlby, 2009). In this regard, capacity to act responsibly gains relevance as sometimes people might be constrained in their ability to act responsibly due to contextual factors (Middlemiss, 2010). A wide range of evidence has emerged indicating that stronger self-importance of moral identity may predict higher rates of responsible actions and less moral disengagement (Kennedy et al., 2017).

Despite the important theoretical and empirical work on moral identity and responsibility, it remains largely overlooked within the context of the P2P accommodation. One notable exception to the lack of research on moral responsibility in P2P accommodation is found in the recent work of Dredge (2017), who uses the $\mathrm{P} 2 \mathrm{P}$ accommodation sector as a context to excavate issues of moral responsibility. Dredge (2017) argues that moral responsibility requires responsiveness to impacts and negative externalities. However, actors in P2P accommodation have displayed differing willingness to act responsibly and their behaviour has often raised controversies on whether P2P platforms reflect the sharing economy philosophy (Farmaki and Kaniadakis, 2018). Dredge (2017) attributes instances of irresponsible behaviour to the dynamic and fluid organisational form of $\mathrm{P} 2 \mathrm{P}$ accommodation, which is resistant to rule-bound approaches to defining and assigning responsibilities. In this context, the responsibilities of various actors can be 
diffused, resulting in lack of accountability or even avoidance. Dredge (2017) acknowledges that greater understanding of the ethical decisions and trade-offs in collaborative economy practices is needed, further commenting that there is a need for specific tools and frameworks.

This is the challenge to which this paper responds, by adopting a moral identity approach to enhance understandings of responsibility in P2P accommodation, with particular emphasis being placed on Airbnb host practices. While issues of trust and transparency were previously examined in relation to Airbnb, these were considered from a guest perspective (e.g. Ert et al., 2016; Yang et al., 2019). As such, little is known of how moral judgements of hosts act as a source for the motivation to behave morally in P2P exchanges. To this end, we sought to: a) evaluate how moral responsibility is understood by Airbnb hosts in relation to their moral identity; and b) to examine how Airbnb hosts' perceptions of moral responsibility inform their hosting practice to perform the hospitality exchange. Specifically, we considered all stages of P2P transactions (pre-transaction, during the hospitality exchange and posttransaction) to understand the 'moral questions' that hosts need to address in each stage and, accordingly, if and how they enact certain aspects of their moral identity in doing so.

\section{Methodology}

Data collection and analysis followed a qualitative research approach. A qualitative approach to research was deemed more appropriate given the aim of the study, as it allowed the in-depth exploration of the complex constructs of host perceptions of moral identity and moral responsibility in relation to their hosting practice. Indeed, qualitative research methods may enable the provision of thick descriptions of people's voices and experiences that uncover new understandings of a phenomenon (Ezzy, 2002). In relation to our study, qualitative research allowed a greater understanding of issues pertinent to responsible host conduct by identifying the factors driving the behaviours and practices of Airbnb hosts.

Data collection was undertaken between November 2018 to February 2019. The sampling process was facilitated by the principal investigator's involvement in a relevant European COST Action, which allowed her access to Airbnb hosts across Europe through workshops, training schools and other events organised by the COST. Specifically, the investigator used the network of the Action to identify Airbnb hosts participating in COST events and, subsequently, invite them to participate in the research via email. In so doing, the researcher informed hosts of the purpose of the study as well as the way in which data would be used, ensuring their anonymity would be maintained. Purposive sampling was used to select Airbnb hosts who were deemed knowledgeable of the topic (Schutt, 2018). According to Robinson (2014), in qualitative studies researchers use their a-priori theoretical knowledge of the phenomenon under study and select individuals they believe are able to offer valuable insights. Hence, for our study, we took into consideration the demographic factors (e.g. backgrounds, age and gender) of the informants to ensure a diverse enough sample was included in the study as per Ritchie et al.'s (2014) suggestion. In other words, participants of both genders and various age groups were targeted across different locations in Europe whereas efforts were undertaken to ensure that hosts on different accommodation types were considered (i.e. shared rooms, entire homes). We opted to focus on European-based Airbnb hosts to ensure some form of consistency and uniformity regarding hosts views, particularly in light of the influence 
of the context (e.g. regulatory framework) on host activities. Data saturation was reached at 35 informants, the profile of which can be seen in table 1 .

$<$ Insert Table 1 about here $>$

Semi-structured interviews of about 45-60 minutes each were undertaken via skype in accordance to informants' date and time preference. All interviews were conducted in English, with the researcher ensuring that the interviewees understood each question asked before proceeding to the next one. In particular, the informants were asked a number of questions, starting from 'grand tour' questions (McCracken, 1988) that aimed to establish the profile of the informants (e.g. number of property listed) before proceeding with questions about host motives and views over moral identity and responsible hosting practices. For instance, the following questions were asked to set the background:

- Why did you decide to become a host?

- Why did you choose to host on the Airbnb platform specifically?

- How important is hosting for you?

These questions allowed us to understand the background and motivation of hosts for engaging in the hosting practice and served as the basis for subsequent questions to be asked on their moral identity and responsibility as Airbnb hosts. For instance, in order to understand the meaning informants attributed to the concepts of 'morality' and 'responsibility' on a personal level and in relation to hosting, we asked:

- Would you say morality is an important aspect that defines your character?

- Can you identify certain moral traits which you think are associated with your character?

- Which moral traits do you think an Airbnb host must have? How do these influence his/her hosting practice?

- What does 'responsibility' mean to you?

- How would you describe a responsible Airbnb host?

Following, additional questions were asked to uncover informants' views over responsible hosting practices at different stages of the exchange, such as:

- What practices do you undertake prior to the exchange to ensure you abide to responsible hosting conduct?

- What practices do you follow during the exchange to maximise responsible hosting conduct?

- What practices do you undertake following the exchange to ensure responsible hosting conduct?

- Are there any instances throughout the exchange where you exhibited irresponsible hosting behaviour? If so, why?

- In what ways does Airbnb provide a mechanism for enhancing responsible hosting conduct? Does it carry any responsibility itself?

- What responsibilities do you think guests have throughout the exchange? 
The questions asked were general and open with the aim of allowing the informants to elaborate on their perceptions and experiences (Patton, 2014). Specifically, the questions asked were used as exploratory themes with the informants being further probed where appropriate. Data were analysed thematically in order to identify key themes within the discussion (Braun and Clarke, 2006). Three researchers were responsible for the analysis of the data. First, the researchers read the interview transcripts and notes multiple times to familiarise with the data. Then, the transcripts were analysed more closely with the three researchers identifying key topics in a "theory-driven" manner (Braun and Clarke, 2006:88). To maximise analytical integrity and ensure data validity, each researcher took on an initial round of open coding separately before converging the first set of findings in a process called triangulation. Flick (2000) posited that investigator triangulation is an effective method to balance subjective research interpretations due to the collective comparison of coding schemes. Hence, in this study researcher triangulation ensured that interviewees' perceptions of moral issues pertaining to their hosting practice are objectively interpreted. Subsequently, axial coding was undertaken whereby emerging topics were grouped into interrelated themes by copying, re-organising and comparing thematic categories whilst refining the data under each theme to identify sub-categories (Goulding, 1999). In this way, thematic categories are expanded and clarified. Last, selective coding was used to combine sub-categories with the themes initially identified; thereby, validating relationships, refining and further developing thematic categories (Strauss and Corbin, 1990) to enhance elaboration on key issues (Hennink et al, 2010). For instance, during open coding the topic of 'motives' was identified; this was then refined and categorised according to 'social motives' and 'economic motives' before being related to the professionalism degree of hosts.

\section{Findings}

\subsection{Motives for hosting on Airbnb}

Initially, we sought to examine the motives of hosts in using Airbnb in order to understand the drivers and background for engaging in hosting. As Krettenauer and Casey (2015: 175) noted, "moral identities differ in underlying motivations and goal orientations". Accordingly, an understanding of hosting motives may deepen knowledge on the motivation of hosts to act responsibly in relation to their practice. Economic opportunities were the most predominant driver identified by most hosts, although it appeared to carry varying degrees of importance for informants. Nearly half of the informants explained that hosting on Airbnb presents a way to earn additional income that allows them to cover personal expenses or subsidise indulgent consumption. For others, Airbnb offers the opportunity of a temporary salary given unexpected personal circumstances (i.e. unemployment). In some cases, the platform emerged as a space of enterprise whereby hosting has become a professional activity. As an informant commented [male, 40, Greece], "I manage more than 50 properties and make a good living from this". Within this context, informants argued that Airbnb, "being the market leader" [male, 38, Czech Republic] of P2P accommodation networks, presents greater economic opportunities than other platforms, which command higher commission fees or are less popular.

Equally, several informants acknowledged social benefits as key motivators for hosting on $\mathrm{P} 2 \mathrm{P}$ accommodation, commenting on the ease of access to Airbnb. In the words of a host [female, 54, Scotland], "there are no prerequisites, everyone can join the platform". Specifically, informants highlighted the socialising opportunities 
offered by the platform, which they distinguished from competing ones on the grounds that "Airbnb is about meeting people...it's different to booking.com" [male, 43, Cyprus], clarifying that "hosting on Airbnb is like hosting friends, not customers" [female, 42, Greece]. Another informant [female, 53, Netherlands] agreed, stating that "Airbnb is an inspiring way [to live...you meet all kinds of people from all over the world". In this regard, the co-habiting option was identified as a marker reinforcing the social benefits of Airbnb, by reflecting hosts' moral principles of helping others. As a host [female, 60, Ireland] aptly put it, "it's not about the money...it's about the people you get to help". Indeed, informants said that the 'sharing practice' entails willingness to "extend a helping hand to those who might need a home away from home" [female, 53, Netherlands]. Within this context, several informants commented on the ability to personalise listings on Airbnb, which allows hosts to "see reviews of guests, understand who they are and what the purpose of their visit is" [female, 31, Germany], thus offering additional security and trust with regard to the $\mathrm{P} 2 \mathrm{P}$ transaction.

As discussion moved on, it became evident that there are different types of Airbnb hosts depending on whether economic or social motives dominate their decision to host on the platform and on how closely they interact with their guests. On the one hand, there are co-habiting hosts, who engage in $\mathrm{P} 2 \mathrm{P}$ accommodation mostly for social reasons and actively interact with guests as they share their space with them. Likewise, there are hosts who rent their entire property on an ad-hoc basis yet manage this themselves and, in most cases, maintain some level of interaction with guests. These informants, upon reflection, identified themselves as 'non-professionals'. On the other hand, there were hosts who manage single or multiple listings either on their own or through another entity (e.g. co-host, professional company). For these informants the hosting activity presents an important source of income while, in some cases, a primary one. Unsurprisingly, these hosts self-identified as 'professional hosts'. Therefore, it appears that hosts may be categorised into professionals and nonprofessionals. Arguably, different hosting motives may signify varying motivation to act responsibly in relation to the hosting practice. To this end, we sought to evaluate the perceived importance of hosts' morality before examining how perceptions of moral identity may generate host judgements of moral responsibility.

\subsection{Airbnb hosts' moral identity and responsibility perceptions}

All of the informants, regardless of their self-assigned professionalism, acknowledged that having high morals was a central aspect of their character, attributing high importance to moral traits such as "being caring and thoughtful of others", "being fair when dealing with others", "maintaining courtesy and transparency in transactions" and "being helpful". Informants argued that such traits are important for hosting practice as they "provide the framework in which P2P transactions take place" [female, 55, UK] and "reflect good hospitality practices" [female, 42, Greece]. In this regard, we asked informants to elaborate on their judgements of moral responsibility and, specifically, describe what responsibility means for them. The majority of hosts reflected on personal values and ethos, making the following comments:

Responsibility has to do with a person's character and way of life.

[male, 34, Estonia]

It is different for every person as it has to do with personal ethics, how one interprets things in life or deals with specific situations and people. 
Within this context, informants related responsibility with "accountability towards others" [female, 38, Spain], "respect for other cultures and different people" [male, 47, Spain] and "keeping your word and doing what it is expected to do" [male, 38, Czech Republic]. In particular, several informants highlighted the importance of "dutiful actions...that we [people] need to take ownership for" [female, 43, UK], stressing the importance of consequences as a result of (ir)responsible behaviour. As such, informants explained that responsible conduct is illustrated by people's obedience to laws and adherence to obligations as a member of the wider society.

Following, we turned our attention to perceptions of moral responsibility in relation to hosting on Airbnb. Specifically, almost half of the informants suggested that "a responsible host will be a responsible citizen" [female, 43, UK]. In other words, hosts argued that responsible hosting practice implies that Airbnb hosts are generally dutiful members of the society. Such thoughts were mostly prevalent among non-professional hosts. Even so, the rest of the informants and mostly professionals pointed towards a distinction between a person's responsible behaviour and his/her hosting practice, arguing that "being an Airbnb host is just one role of many that hosts have to play" [male, 32, Greece]. Specifically, informants did not regard hosting practice as necessarily related to the degree of responsibility a person exhibits in their professional or personal life. Neither did informants thought hosting practice to be indicative of the morality of the host. Such views were surprising considering that all of the informants identified morality as a central aspect of their character and sense of self. Hence, we sought to understand how hosts adopt aspects of moral identity in their hosting practice and, subsequently, how they externalise their self-perceptions of moral responsibility through relevant activities. In doing so, we asked informants to elaborate on specific moral responsibilities as they become relevant at different stages of the P2P hospitality exchange. A summary of Airbnb hosts' moral responsibilities as emerging from the interviews is provided in table 2 , with host practices being explained in detail in the following section.

$<$ Insert Table 2 about here $>$

\subsection{Airbnb host practices}

\subsubsection{Pre-transaction phase}

Prior the transaction, both professional and non-professional hosts identified platformrelated practices as a key activity, including developing and communicating their property descriptions and screening potential guests' profile in order to evaluate their suitability before accepting booking requests. Informants suggested that when undertaking these practices, the issues of transparency and inclusivity emerge as relevant to moral identity, guiding their activities accordingly. "If you say your property is 100 square metres then it should be 100 square metres" said a host [male, 45 , Greece] commenting on the need for honesty in communicating the offering. Within this context, informants highlighted the freedom to personalise listings as a benefit of Airbnb, which further elevates the importance of "transparency as a mechanism for good host conduct" [female, 30, Cyprus]. As a host [female, 36, Sardinia] put it, "there are cases where hosts exaggerate and give false representations of the property". In this regard, the role of the platform was emphasised as providing guidance to hosts, especially to non-professional ones. 
Indeed, several informants argued that they seek advice from the platform itself when developing the property descriptions. "You need to agree to the rules of the platform to register, in other words hosts need to provide a fire detector and extinguishers, toiletries and so on" explained an informant [male, 45, Cyprus]. In this regard, the support of online host groups was mentioned as influential on host practices, particularly for less experienced, non-professional hosts. Professional hosts with multiple listings were more inclined to use appealing visual narratives that convey "the offering of experiences than simply list the things that the property has" [male, 37, Czech Republic] in order to maximise their business. For these hosts, transparency emerged as an important business practice that may lead to positive word-of-mouth and higher guest satisfaction.

Additionally, informants pointed to the anti-discrimination policy of Airbnb as a restrictive factor on their hosting practice, arguing that greater flexibility is required in guest selection. Such views were strongly expressed by non-professional hosts. As a host commented:

You can attribute bad behaviours on specific parameters such as nationality or age...for example, I don't accept booking requests from large groups of young, British men as they usually get drank and make noise.

[male, 33, Netherlands]

In some extreme cases, cultural stereotyping was reflected in informants' explanations. For example, a host [male, 27, Cyprus] said he declines requests from potential guests from specific countries or religions. Other hosts, especially cohabiting ones, suggested that they should have the freedom to select who stays in their properties due to safety concerns. The following extracts reflect relevant concerns of hosts.

It is not clear what ensues if something happens to the guest in the property...so I avoid bookings from old people.

[male,45, Greece]

I am a single mother of two girls, I accept only women in my house but with Airbnb's changing policy I feel I am being punished for being selective.

[female, 41, UK]

Indeed, more than half of the informants commented on the platform's introduction of the 'superhost' badge that limits hosts' ability to reject or cancel bookings. As a host [female, 43, UK] stated "if you cancel a reservation for whatever reason, you can't be a superhost for a year". Concerns over Airbnb's policy were expressed particularly by non-professional hosts whether co-habitation exists or not; for these informants, the superhost badge represents a significant booster on their bookings as well as an affirmation of their "good hosting". Contrary, professional hosts with multiple listings tend to "accept all bookings as this is good business" [male, 38, Czech Republic]. Informants suggested that as non-professional hosts, there is "inability to meet some guests' expectations... it's about what I can provide as $a$ host" [female, 43, UK]. In fact, nearly all of the informants discussed the increasing demands of guests, who "think hosts are available 24/7" [male, 40, Greece]. "Some 
guests think that Airbnb properties are like hotels but it's about sharing" argued another host [male, 47, Spain]. For non-professionals and especially co-habiting hosts, guest rejection is not equated to discrimination. As an informant [male, 47, Spain] explained, "I reject on a regular basis. But rejecting guests is not the same as discrimination".

Within this context, nearly all of the informants identified the platform as a driver of guest expectations. As a host said:

Airbnb is becoming increasingly professionalised. Its guidelines are pointing towards a standardisation of service which is comparable to hotels but the hotel sector is regulated...having less flexibility to select guests means that hosts are exposed.

[male, 39, Denmark]

In this regard, non-professional informants explained that initiatives such as Airbnb Plus, used to categorise 'quality' properties, are adding pressure on their hosting practice which is nonetheless being applied within an unregulated context. While informants acknowledged that "hotels don't have the luxury to screen guests" [male, 33, Netherlands] contrary to Airbnb hosts who may go over reviews and guest ratings, they did emphasise the regulated framework in which hotels operate, which is insofar absent in P2P accommodation. An informant [male, 40, Greece] argued "Airbnb started as the foundation of the sharing economy. Now, it has turned into a business-oriented company yet it is located in this grey area where there are laws but there is no enforcement of laws". Such views were equally shared by professional and non-professional hosts.

\subsubsection{During hospitality exchange phase}

Moving on, we asked informants to describe the hosting practice during the hospitality exchange phase, that is after booking request was accepted. "Being hospitable is common sense" argued an informant [female, 53, Netherlands] whereas another host [female, 60, Ireland] added that "if you treat your guests like you treat your friends then you cannot go wrong". For nearly all of the informants, acts of hospitableness and courtesy were key elements of the service provision although these were expressed varyingly. For instance, some co-habiting hosts suggested that they may offer additional services to their guests such as "cook breakfast for them or do pick-ups from the airport" [female, 60, Ireland] while others argued that they are either unable or unwilling to offer such services. As an informant explained:

\section{I treat my guests like I treat my flatmates to manage expectations, so I expect them to do the dishes and cook their own food.}

[female, 38, Spain]

In this regard, informants stated that they not only outline property rules on the platform but also explicitly articulate them to guests either verbally on a one-to-one basis or by leaving an information booklet in the property. In any case, all of the hosts irrespective of their degree of professionalism acknowledged that they are responsible for providing a safe, clean, functional environment to their guests and ensure that service provision matches their listing description in order to "build trust with guests" [female, 60, Ireland]. Indeed, transparency and trust emerged as an important moral aspect of hosting practice, particularly for co-habiting hosts. In the words of an informant: 
You hear stories of hosts putting up cameras in the properties to monitor guests but this is unethical...we open up our home to strangers but they also need to trust us.

[female, 43, UK]

Moreover, being organised and maintaining communication with the guest before arrival at the property were also acknowledged as key elements of being a responsible host. As an informant [female, 31, Germany] put it, "I need to be reachable for my guests in case something happens". Indeed, several hosts argued that they provide booklets with contact details and relevant tourist information to guests. Such services seem to be comparable to professional hotel standards; nonetheless, findings reveal that they are evident in the practices of both professional and non-professional hosts. In this context, informants argued that guests too have responsibilities towards the hosts. For instance, informants stated that guests need to respect the property rules, ensure they will not cause damage to the property and respect the neighbours as well as the privacy of the host, particularly in case of co-habitation. As an informant [female, 60, Ireland] put it, "guests need to be thoughtful of the host. For example, if they are going to arrive late, they need to inform the host accordingly". As such, various incidents were described by hosts as indicative of guests' poor conduct. The text below acts as an exemplar of such incidents:

I was sitting in the living room, chatting with a guest when he suddenly took the remote control and changed the TV channel. But I was watching a programme. I thought...hang on, this is my TV, my living room!

[female, 43, UK]

Another informant [female, 53, Netherlands] described how one guest smoked inside the property despite the 'no smoking' warning and when confronted he simply carried on, stating that he was smoking a pipe and not a cigarette. As such, hosts and especially non-professional ones suggested that "only Airbnb can regulate the irresponsible behaviours of guests and hosts... by setting standards" [female, 43, UK]. Nonetheless, as hosts pointed to the "guest-first approach" advocated by Airbnb's changing policies, they described themselves as "hostages of the platform" [male, 27, Cyprus] unable to overpower guests who might in turn give them bad reviews.

Other incidents were mentioned with respect to guests' misconduct and/or disturbing behaviour against neighbours. Arguing that respect to neighbours is a reflection of civilian responsibility, hosts suggested that maintaining good neighbourly relations is an important host practice, particularly for non-professional hosts.

I have to be a responsible Airbnb host for my neighbours...I generally try to avoid inflicting harm on others. I don't want to benefit myself but damage others in the process of doing so.

[female, 44, Italy]

I have to see my neighbours everyday, so I don't want any problems with them.

[male, 34, UK] 
In this context, some hosts highlighted the role of co-hosts on influencing neighbour relations. "I gave the management of my property to a co-host but since then I've been getting complaints from my neighbours and started to receive bad reviews from guests" [female, 38, Spain]. As such, informants stated that they warn guests to behave responsibly within the property and in communal areas of apartment building out of respect for neighbours. Even so, informants suggested that the degree to which such measures are successful vary, further reinforcing the need for guest selection.

\subsubsection{Post-transaction phase}

At the post-transaction phase, the majority of informants (both professionals and nonprofessionals) saw their practice as extending towards adherence to relevant laws, providing reviews for guests and supporting the Airbnb community such as through offering of information to fellow hosts on online social groups. For instance, in their dealings with the platform and the Airbnb society, most informants emphasised the importance of politeness when conducting reviews, honesty and transparency as well as being considerate so as to offer truthful information about others (guests) and to others (other hosts); thus, contributing to the Airbnb community. These values were correspondingly manifested through their active participation in host groups where, non-professional hosts in particular, exchange knowledge and information on hosting practices. Such channels represent the self-organising tactics of professional and nonprofessional hosts. In the words of an informant [male, 33, Netherlands] "we got an accountant, a lawyer and we sought the knowledge of more experienced hosts from San Francisco". As Airbnb hosts are beginning to acquire a 'professional identity', informants engaging in $\mathrm{P} 2 \mathrm{P}$ transactions for professional reasons expressed a desire for greater regulation in order to safeguard their hosting practice as well as obtain a legitimate stance. Such views are regarded as prevalent by informants in the current $\mathrm{P} 2 \mathrm{P}$ accommodation context where guests appear to gain power. "Some guests might give bad reviews out of spite because the host told them off for doing something they shouldn' $t$ ' explained an informant [female, 42, Germany]. In this regard, the importance of reading the general profile of users was highlighted, with hosts suggesting that the platform should consider the potential inciteful behaviour of guests and its effect on host ratings. Indeed, as one professional host [male, 40, Greece] put it, some guests attempt to 'punish' the host by giving bad reviews or breaking and stealing objects from the property as "a last act of showing customer power". The informants implied that guest misconduct elicits negative criticism for Airbnb and highlighted the need for hosts to remain "responsible for the Airbnb community otherwise it will gain a bad name” [male, 47, Spain].

Arguably, the most recurrent theme dominating discussion on post-transaction practices was payment of taxes. Although half of the informants suggested they pay taxes as this is the "right thing to do", the rest stated otherwise. Specifically, most professional hosts admitted to following the law on tax payment as this is a reflection of good business practice. Contrary, many non-professional and especially cohabiting hosts said they avoid declaring Airbnb revenue. In justifying such actions, informants stated that they don't make a lot of money and, hence, it would be "unfair to pay taxes when the revenue is so small" [male, 44, Italy]. Indeed, some co-habiting hosts argued that in certain European countries hosts renting a room in their property and making less than a specific amount per year are exempted from tax payment. Even so, several non-professional hosts commented that avoidance of tax payment is morally permissible as "others avoid paying taxes too" [male, 32, France]. Evidently, 
a form of irresponsible behaviour traverses as a norm in situations where there is collective irresponsibility of Airbnb hosts.

Within this context, both professional and non-professional hosts pointed to the role of the platform on minimising negative socio-economic impacts. As a host [male, 33, Netherlands] commented, "Airbnb needs to create value for everyone...currently, it is disadvantaging hosts. You can't operate at the scale and not take up your share of responsibility". In this regard, informants suggested that Airbnb should collect tax from hosts. "If the company could provide this service to hosts, it would solve many problems" said an informant [female, 38, Spain]. Informants also commented on the pressures being placed on local housing markets as a result of the growth and professionalisation of Airbnb as well as the illegal operation of many Airbnb rentals. Even though many non-professional hosts were particularly concerned over such impacts, several professional hosts did not envisage these consequences as pertinent to their hosting practice, commenting that "hosts cannot be accountable for all the problems in the society and economy" [male, 32, Greece]. Rather, informants stated that the platform "needs to be held accountable not only towards the guests or hosts but to all the parties involved, as its growth is affecting everyone from the hoteliers to residents" [female, 36, Italy]. The words of an informant sum up the feelings of both professional and non-professional hosts:

As Airbnb grows, its effects get bigger on housing, prices, crime, deviant behaviour of hosts and guests...they can't be exempted from the responsibility they have to users, the authorities and the society...we [hosts] are only a piece of the puzzle.

[male, 39, Denmark]

These dynamics are evident in figure 1, which shows the role of the platform in shaping the application of host and guest responsibilities.

$<$ Insert Figure 1 about here $>$

\section{Discussion}

Study findings reveal that Airbnb hosts regard moral traits as central to their sense of self. In this context, hosts expressed the need for responsible behaviour, manifested by efforts to "contribute to the community" or "abide by local rules"; thus, adhering to perceptions of a dutiful citizenship (Powell, 2012). Hosts' moral identity seemed, in principle, to motivate their moral functioning; indeed, to be morally responsible one has to follow through in moral action (Blasi, 1993). Nonetheless, in relation to their hosting practice, there were hosts who distinguished between responsible citizenship and responsible host conduct, arguing that being an Airbnb host is just one role of many that one is called to play and, as such, not necessarily indicative of a person's morality. This fits well with the concept of moral identity centrality (Reed, 2002), in that some hosts assigned what they perceived as their moral identity a central role in their hosting practices while others saw their moral identity as completely separate to these. While prior studies identify moral identity centrality as an influencing factor on the moral disengagement of certain unethical behaviour (e.g. He and Harris, 2014), our study findings suggest that individuals' moral identity centrality varies in accordance to specific roles acquired in different contexts. For some informants, then, their moral self-concept (internalisation) did not necessarily self-regulate their behaviour as hosts (symbolisation). 
In addition, findings indicate a variance in hosts' (ir)responsible behaviour across the different stages of P2P transactions (table 2), with informants' motive and approach to hosting and their perceptions of moral responsibility emerging as key influencing factors on host practice heterogeneity. For instance, there were informants who see themselves as 'professional hosts', renting one or multiple listings systematically with the purpose of gaining a primary source of income as previously reported (e.g. Lutz and Newlands, 2018). Likewise, there were informants who selfidentified as 'non-professional Airbnb hosts', sharing a room in their property or renting out the entire property on an ad-hoc basis to supplement their income and/or for socialising reasons. These informants emerge as 'social entrepreneurs' who are mostly interested in life experiences (Farmaki et al., 2020; Stabrowski, 2017). In fact, a theme which recurred throughout the interviews was that hosts have varying degrees of professionalism; in other words, they differ with regard to the degree of expertise and commitment they bring to their role as hosts on the platform. Within this context, professional and non-professional hosts expressed varying practices and, as such, heterogeneous responsible behaviours. Indeed, previous studies highlighted the illegal operation of many Airbnb rentals and the emergence of professional hosts as the root to the problems caused by Airbnb's expansion (e.g. Gottlieb, 2013; Guttentag, 2015; Stergiou and Farmaki, 2019).

While both professional and non-professional hosts offer services comparative to hotels as previously reported (Dann et al., 2019; Guttentag and Smith, 2017), the way hosts express 'hospitableness' differs. For example, some co-habiting hosts provide more services than others (i.e. cook breakfast); contrary, other informants perceive their hosting responsibilities as having certain boundaries. Although such discrepancies in hosting practices were more evident among non-professional hosts, for hosts self-identifying as 'professionals' a standardised service comparable to traditional hospitality emerged as a key aim, representing good business practice (Farmaki et al., 2020) that facilitates trust-building and enhances their reputation in line with prior research (e.g. Ert et al., 2016; Yang et al., 2019). Similarly, variance was noted among professional and non-professional hosts in terms of responsible behaviour extending to other parties beyond the guest. For instance, non-professional hosts expressed concerns over the potential impacts of their hosting practice on their neighbours, whom they interact with regularly. Indeed, past studies identify neighbours as a significant stakeholder group that needs to be considered in the regulation of the P2P accommodation phenomenon (Stergiou and Farmaki, 2019). Contrary, as our findings reveal, for 'professional' hosts a responsible hosting behaviour represents appropriate professional practice, mostly seen as a means for business maximisation rather than emanating from moral values. Evidently, the moral identity of Airbnb hosts emerges as an important factor directing their behaviour and, in turn, determining the intensity of impacts resulting from the growth of the platform and which threatens the sustainability of places (Ioannides et al., 2018).

Even so, the extent to which professional and non-professional hosts assume responsibility for their actions varies as perceptions of moral responsibility differ, exemplifying accordingly the various degrees of moral identity centrality in informants' hosting practices. As such, professional and non-professional hosts alike appear to justify irresponsible acts (Linley and Matlby, 2009) highlighting the context of P2P transactions as influential on their ability to exercise hosting practices responsibly (Middlemiss, 2010). Indeed, two factors appear to contribute to their reasoning. First, a similar irresponsible action being followed by other hosts (i.e. avoidance of tax payment); such form of irresponsible behaviour traverses as a norm 
because of the collective behaviour of Airbnb hosts that seems to reinforce their moral disengagement (Kennedy et al., 2017). In such cases, the moral identity of hosts is woven together with the actions of relevant others, which serve as the backdrop of their own decision on what is morally acceptable in this situation. Second, the lack and inconsistency of a regulatory framework on P2P accommodation seems to exacerbate irresponsible acts of hosts especially when the likelihood of being detected is minimal (Park et al., 2019). Specifically, findings identify hosts who attempt to self-regulate their practice in an effort to attribute responsibility to themselves. As collective responsibility is difficult to establish (Kaufman, 2015) particularly where there is absence of a formal regulatory framework as in the case of P2P accommodation (Rauch and Schleicher, 2015), individuals tend to either assign responsibility to themselves or diffuse responsibility to others (McGregor, 2017). Host views express an embedded assumption that hosts are not accountable for their irresponsible actions that arise due to the conditions that exist within the P2P context including the illegal activity of many Airbnb rentals (Gottlieb, 2013; Guttentag, 2015). In this regard, some hosts tend to diffuse responsibility to the platform or even to guests whom they regard as equally responsible.

This study concludes that there are various ways in which hosts draw on their moral identity to guide their practice. To be able to start comprehending and articulating the complexities of the relationship between moral identity and responsible host conduct, we found it necessary to devise a mechanism that would allow us to develop understandings of the variety of ways in which moral identity affects hosting practice. To this end, we offer a typology (figure 2) of Airbnb hosts linking their understanding of moral identity as a self-assigned construct guiding their behaviour with the level of what we call here 'professionalism' in hosting practice, namely their approach to hosting as shaped by the primary motive to engage in $\mathrm{P} 2 \mathrm{P}$ transactions (i.e. economic or social) and the degree of commitment and hospitality expertise they bring to their role as hosts. In other words, different types of hosts seem to exist in relation to whether their hosting practice reflects high or low moral identity and in accordance to their categorisation as high professionals (e.g. managing multiple listings for economic benefits) or low professionalism (e.g. sharing property for socio-economic benefits). Specifically, the typology illustrates a spectrum of Airbnb hosts: a) those emerging as moral agents in P2P accommodation viewing their hosting practice as an extension of their moral self, with their hosting practice not being driven by economic reasons but a desire to help others in need, b) agentic hosts who have a practical view in terms of their morality that seems to define their professional identity by safeguarding their reputation and so engage in self-regulating tactics (i.e. consulting accountants), c) opportunistic hosts who are hosting professionally and define their practice according to economic interests, thus conform only to the minimum requirements of the law (e.g. paying taxes) as a means of protecting their professional resources and d) amoral hosts who justify immoral behaviour in the context of situational factors present in the external environment including the lack of a regulatory framework on P2P accommodation and/or in relation to peers' irresponsible behaviour.

$<$ Insert Figure 2 about here $>$

\section{Conclusions}

This study aimed to explore the perceptions of Airbnb hosts with regard to their moral responsibility in $\mathrm{P} 2 \mathrm{P}$ transactions. By drawing from moral identity theory, we sought 
to understand how Airbnb host views on moral responsibility are generated and how their hosting practice is linked to personal motivation to act responsibly. Given the growing concerns voiced by scholars with regard to the effects of Airbnb (i.e. Ioannides et al., 2018; Stergiou and Farmaki, 2019) which seem to be largely driven by the unscrupulous behaviour of hosts and threatening the sustainability of places (Martin, 2016), this study is a timely addition to the expanding literature on P2P accommodation. Although past studies have considered issues pertinent to trust and transparency in P2P practice (e.g. Ert et al., 2016; Yang et al., 2019), little is known of how hosts are motivated to behave morally throughout the different stages of the P2P exchange. This study responds to this gap and attempts to shed light on the 'moral questions' that hosts need to address in each stage and, accordingly, how they enact certain aspects of their moral identity in their hosting practice.

As the preceding discussion illustrated, hosting in P2P accommodation settings is fraught with moral issues. On the one hand, this study identified several examples of moral actions that hosts undertake to enhance transparency, hospitality provision and trust-building in line with past studies (Farmaki et al., 2020; Moon et al., 2019). On the other hand, there are morally irresponsible behaviours emerging that can take many forms such as tax avoidance, guest discrimination and providing misleading property information among others. Such behaviours were identified by researchers as a matter of concern requiring the regulation of the Airbnb phenomenon as they inevitably impact the socio-economic fabric of local communities (i.e. Gurran and Phibbs, 2017); further contributing to the negative effects emanating from overcrowding and the touristification of places (Ioannides et al., 2018) that result from the growth of illegal or professional operation of Airbnb rentals (Gottlieb, 2013; Stergiou and Farmaki, 2019). Indeed, as the study has shown, Airbnb hosts emerge as a 'community of practice' (Farmaki and Kaniadakis, 2018) and, thus, their potentially irresponsible behaviour becomes a norm, acting as a justifiable principle guiding the behaviour of their peers. Nonetheless, as this study has shown, there are various ways in which Airbnb hosts draw on their moral identity to inform their hosting practice, often according to the context in which they operate, wherein the absence of regulation reinforces moral disengagement (Kennedy et al., 2017). In order to capture the complexity of moral identity within $\mathrm{P} 2 \mathrm{P}$ accommodation, this study identifies and illustrates in figure 2 four types of hosts that exhibit different behaviours in accordance to their degree of professionalism and moral identity levels.

The typology, thus, makes a two-fold contribution to existing knowledge. First, it can be understood as an analytical tool that allows scholars to identify hosting behaviour, articulate causal relations, devise new research questions and design research within $\mathrm{P} 2 \mathrm{P}$ accommodation. The typology enhances understanding of host behaviour as a response to certain moral responsibilities, as these emerge out of the different stages of the $\mathrm{P} 2 \mathrm{P}$ exchange. In other words, hosts interpret their hosting practice as a set of certain responsibilities that either have a direct internal link to specific moral traits or are associated with broader social and community values. Subsequently, their hosting practice is drawn according to what would be the response to relevant moral questions. Each response, then, could be categorised and understood in the moral identity-professionalism matrix of the host typology. Secondly, it may be conceptualised as a diagnostic and reflective tool for hosts or those considering of becoming hosts. The typology may allow hosts to reflect on their own approach to hosting and understand their levels of moral engagement into their P2P activity, suggesting a self-reflective understanding of the self as host. Specifically, as hosts' identity switches between them being property owners and/or 
hospitality professionals and entrepreneurs, the typology may allow them to draw a personal strategy and decide where the boundaries between morality and hosting would lie. In other words, the typology can be seen as an action template for Airbnb hosting, one that takes into consideration the moral aspects of the practice. This is relevant given the diverse hosting approaches characterising $\mathrm{P} 2 \mathrm{P}$ accommodation and associated effects on local communities and economies (Farmaki et al., 2020).

The typology also carries significant practical implications. Our findings suggest that while moral identity does act as a self-regulatory mechanism in inhibiting unethical host practices, the effect of this self-regulation may be rendered less potent by contextual factors. Considering the growth of $\mathrm{P} 2 \mathrm{P}$ accommodation and the potential socio-economic impacts it yields at the local, regional and national levels, self-regulation presents an inadequate mechanism for monitoring the sector. Accordingly, regulatory efforts should first consider the variance among P2P accommodation hosts and not treat them as a homogeneous group. Although categorising different types of hosts is not an easy task, as some may shift from one type to another over time, it is necessary to align regulatory controls to specific host categories to ensure maximum benefit for the parties involved. For instance, hosts may be categorised with regard to the degree of 'professionalism' they carry in their hosting approach and be regulated accordingly in terms of taxation and occupancy among others. Additionally, regulation should be targeted not only to hosts but also to other actors involved in the P2P transaction including guests, neighbours and the platform itself. As this study betrays, the dynamics among relevant stakeholders are to a great extent influential on hosts' assumed ability to carry out their practice responsibly. In particular, regulatory efforts should focus on eliminating those influences that motivate hosts to act irresponsibly.

Alternatively, policies may be directed at invoking a desired "ideal citizenship" (Haber and Levi-Faur, 2018:242), encouraging moral host behaviour. In the political sphere, citizenship represents "a relation between the individual and the community, a membership status which contains a package of rights, duties and obligations" (Faulks, 2000:13). Building on this conceptualisation, the equivalent of political citizenship in the $\mathrm{P} 2 \mathrm{P}$ accommodation sphere would relate to a set of rights and values based on a strong moral element of the individual host as a participant in P2P activities. As such, Airbnb may incorporate relevant features in its platform to reward and encourage morally responsible host conduct. Such policies might include a badge comparable to the 'superhost' one that Airbnb already offers. Likewise, the platform might adopt a social responsibility strategy equivalent to the corporate social responsibility strategies of organisations in order to promote responsible host and guest behaviour that contributes to the sustainability of destinations. Regardless, such efforts should aim to develop a culture that upholds the broader community's moral values rather than simply those of personal aspirations and business ideals.

To conclude, this study identified both morally responsible and irresponsible acts of Airbnb hosts which indicate that P2P accommodation offers a fruitful landscape for further examination of the interplay between moral identity and hosting practices. Ultimately, articulating a fuller understanding of the role of moral identity and responsibility in $\mathrm{P} 2 \mathrm{P}$ accommodation contexts will require the development of a comprehensive framework relating to when and how moral identity will exhibit selfregulatory potency to act responsibly. By making a case that responsible host conduct varies as a function of hosts' professionalism and self-perceived moral identity, we have taken a step towards this direction. Investigations aimed at mapping out what situational factors have the greatest potential to influence the relationship between 
hosts' moral identity and moral behaviour are needed to build on this initial effort. Moreover, there is a need to understand how guests perceive moral identity aspects in P2P transactions. We hope that the ideas presented in this study can provide researchers with an impetus to investigate these and other questions associated with (im)morality in the P2P accommodation context.

\section{References}

Airbnb (2018). Airbnb Fast Facts.

Available at:https://press.atairbnb.com/app/uploads/2017/08/4-Million-Listings-

Announcement-1.pdf [accessed 5 January 2018]

Aquino, K. and Reed, A. II (2002). The self-importance of moral identity. Journal of Personality and Social Identity, 83(6): 1423-1440.

Belk, R. (2014). You are what you can access: Sharing and collaborative consumption online. Journal of Business Research, 67(8): 1595-1600.

Beu, D., \& Buckley, M. R. (2001). The hypothesized relationship between accountability and ethical behavior. Journal of Business Ethics, 34(1): 57-73.

Blasi, A. (1993). The development of identity: Some implications for moral functioning. In: G.G. Noam and T.E. Wren (Eds.), The Moral Self. Cambridge, MA: The MIT Press (pp. 99-122).

Braun, V., \& Clarke, V. (2006). Using thematic analysis in psychology. Qualitative research in psychology, 3(2): 77-101.

Bucher, E., Fieseler, C., Fleck, M., \& Lutz, C. (2018). Authenticity and the sharing economy. Academy of Management Discoveries, 4(3): 294-313.

Caton, K. (2012). Taking the moral turn in tourism studies. Annals of Tourism Research, 39(4): 1906-1928.

Cheng, M., \& Foley, C. (2018). The sharing economy and digital discrimination: The case of Airbnb. International Journal of Hospitality Management, 70: 95-98.

Cohen, M., \& Sundararajan, A. (2015). Self-regulation and innovation in the peer-topeer sharing economy. University Chicago Legal Review Dialogue, 82(1): 116-119.

Cohen, B., \& Munoz, P. (2016). Sharing cities and sustainable consumption and production: towards an integrated framework. Journal of Cleaner Production, 134: 87-97.

Damon, W. and Hart, D. (1992). Self-understanding and its role in social and moral development. In: M. Bornstein and M.E. Lamb (Eds.), Developmental Psychology: An Advanced Handbook ( $3^{\text {rd }}$ ed.). Hillsdale, NJ: Erlbaum (pp. 421-464).

Dredge, D., \& Gyimóthy, S. (Eds.) (2017). Collaborative Economy and Tourism: Perspectives, Politics, Policies and Prospects. Cham: Springer. 
Edelman, B. G., \& Geradin, D. (2015). Efficiencies and regulatory shortcuts: How should we regulate companies like Airbnb and Uber. Stanford Technological Law Review, 19(2): 293-297.

Erikson, E. H. (1964). Insight and Responsibility. New York: Norton.

Ert, E., Fleischer, A., \& Magen, N. (2016). Trust and reputation in the sharing economy: The role of personal photos in Airbnb. Tourism Management, 55: 62-73.

Espinosa, T. P. (2016). The cost of sharing and the common law: How to address the negative externalities of home-sharing. Chapman University Law Review, 19(2): $597-$ 601 .

Ezzy, D. (2002). Qualitative Analysis: Practice and Innovation. London: Routledge.

Farmaki, A., Christou, P., \& Saveriades, A. (2020). A Lefebvrian analysis of Airbnb space. Annals of Tourism Research, 80: ahead-of-print.

Farmaki, A., \& Kaniadakis, A. (2018). Responsibility in the sharing economy. Proceedings of the 28th CAUTHE conference, Newcastle Business School, The University of Newcastle, Australia (pp. 553-556).

Faulks, K. (2000). Citizenship. London: Routledge

Flick, U. (2000). An introduction to qualitative research. European Journal of Information Systems, 9(2): 127-127.

Gottlieb, C. (2013). Residential short-term rentals: Should local governments regulate the 'industry'?. Planning \& Environmental Law, 65(2): 4-9.

Goulding, C. (1999). Grounded theory: Some reflections on paradigm, procedures and misconceptions. Working paper series, WP006/99, Wolverhampton: University of Wolverhampton.

Grimmer, L., Vorobjovas-Pinta, O., \& Massey, M. (2019). Regulating, then deregulating Airbnb: The unique case of Tasmania (Australia). Annals of Tourism Research, doi: 10.1016/j.annals.2019.01.012.

Gurran, N., \& Phibbs, P. (2017). When tourists move in: How should urban planners respond to Airbnb?. Journal of the American Planning Association, 83(1): 80-92.

Guttentag, D. (2015). Airbnb: Disruptive innovation and the rise of an informal tourism accommodation sector. Current Issues in Tourism, 18(12): 1192-1217.

Haber, H., \& Levi-Faur, D. (2018). The financialization of European Union citizenship: An alternative to democratic empowerment. In: D. Levi-Faur and F. van Warden (Eds.), Democratic Empowerment in the European Union. Cheltenham: Edward Elgar (pp. 239-268).

Hajibaba, H., \& Dolnicar, S. (2017). Substitutable by peer-to-peer accommodation networks?. Annals of Tourism Research, 66: 185-188. 
Hardy, S. A., Bhattacharjee, A., Reed, A. II, \& Aquino, K. (2010). Moral identity and psychological distance: The case of adolescent parental socialization. Journal of Adolescence, 33(1): 111-123.

He, H., \& Harris, L. (2014). Moral disengagement of hotel guest negative WOM: moral identity centrality, moral awareness, and anger. Annals of Tourism Research, 45: 132-151.

Hennink, M., Hutter, I., \& Bailey, A. (2010). Qualitative Research Methods. London: Sage.

Ikkala, T., \& Lampinen, A. (2015, February). Monetizing network hospitality: Hospitality and sociability in the context of Airbnb. In Proceedings of the 18th ACM conference on computer supported cooperative work \& social computing (pp. 10331044). ACM.

Ioannides, D., Röslmaier, M., \& van der Zee, E. (2018). Airbnb as an instigator of 'tourism bubble' expansion in Utrecht's Lombok neighbourhood. Tourism Geographies, doi: 10.1080/14616688.2018.1454505.

Jonas, A. (2015). Share and share dislike: The rise of Uber and Airbnb and how New York City should play nice. Journal of Law \& Policy, 24(1): 205-215.

Kaufman, B. (2015). Theorising determinants of employee voice: An integrative model across disciplines and levels of analysis. Human Resource Management Journal, 25(1): 19-40.

Kennedy, J. A., Kray, L. J., \& Ku, G. (2017). A social-cognitive approach to understanding gender differences in negotiator ethics: The role of moral identity. Organisational Behaviour and Human Decision Processes, 138: 28-44.

Krettenauer, T., \& Casey, V. (2015). Moral identity development and positive moral emotions: Differences involving authentic and hubristic pride. Identity: An International Journal of Theory and Research, 15(3): 173-187.

Lalicic, L., \& Weismayer, C. (2017). "The role of authenticity in Airbnb experiences". In Schegg, R. and Stangl, B. (Eds.) Information and communication technologies in tourism 2017 (pp. 781-794). Springer, Cham.

Linley, P. A., \& Maltby, J. (2009). "Personal responsibility” In: S. J. Lopez (Ed.), The Encyclopedia of Positive Psychology. Boston, MA: Blackwell Publishing (pp. 685689).

Lutz, C., \& Newlands, G. (2018). Consumer segmentation within the sharing economy: The case of Airbnb. Journal of Business Research, 88: 187-196.

Martin, C. J. (2016). The sharing economy: A pathway to sustainability or a nightmarish form of neoliberal capitalism?. Ecological economics, 121: 149-159.

McCracken, G. (1988). The Long Interview (Vol. 13). London: Sage Publications. 
McGregor, S. L. (2017). Consumer perceptions of responsibility. In: G. Emilien, R. Weitkunat and F. Lüdicke (Eds.), Consumer Perception of Product Risks and Benefits. Springer: Cham (pp. 567-596).

Middlemiss, L. (2010). Reframing individual responsibility for sustainable consumption: Lessons from environmental justice and ecological citizenship. Environmental Values, 19(2): 147-167.

Mody, M., Suess, C., \& Dogru, T. (2019). Not in my backyard? Is the anti-Airbnb discourse truly warranted? Annals of Tourism Research, 74:198-203.

Mody, M., Hanks, L., \& Dogru, T. (2019). Parallel pathways to brand loyalty: Mapping the consequences of authentic consumption experiences for hotels and Airbnb. Tourism Management, 74: 65-80.

Mulder, L. B., \& Aquino, K. (2013). The role of moral identity in the aftermath of dishonesty. Organizational Behavior and Human Decision Processes, 121(2): 219230 .

Nieuwland, S., \& van Melik, R. (2018). Regulating Airbnb: How cities deal with perceived negative externalities of short-term rentals. Current Issues in Tourism, doi: 10.1080/13683500.2018.1504899.

Park, S. K., Kwak, K. T., \& Lee, B. G. (2019). Policy compliance and deterrence mechanism in the sharing economy. Internet Research, 29(5): 1124-1148.

Paulauskaite, D., Powell, R., Coca-Stefaniak, J. A., \& Morrison, A. M. (2017). Living like a local: Authentic tourism experiences and the sharing economy. International Journal of Tourism Research, 19(6): 619-628.

Patton, M. Q. (2002). Qualitative research and evaluation methods. London: Sage Publications.

Power, F. C., \& Khmelkov, V. T. (1998). Character development and self-esteem: Psychological foundations and educational implications. International Journal of Educational Research, 27(7): 539-551.

Rauch, D. E., \& Schleicher, D. (2015). Like Uber, but for local government law: The future of local regulation of the sharing economy. Ohio State Law Journal, 76: 901.

Reed, A. II (2002). Social identity as a useful perspective self-concept-based consumer research. Psychology and Marketing, 19(3): 235-266.

Reed, A., Aquino, K., \& Levy, E. (2007). Moral identity and judgments of charitable behaviors. Journal of Marketing, 71(1): 178-193.

Ritchie, J., Lewis, J., Nicholls, C. M., \& Ormston, R. (2014). Qualitative Research Practice ( $4^{\text {th }}$ ed.). Los Angeles, CA: Sage

Robinson, O. C. (2014). Sampling in interview-based qualitative research: A theoretical and practical guide, Qualitative Research in Psychology, 11(1): 25-41. 
Schutt, R. K. (2018). Investigating the Social World: The Process and Practice of Research. London: Sage Publications.

Seeley, E. A., \& Gardner, W. L. (2003). The "selfless" and self-regulation: The role of chronic other-orientation in averting self-regulatory depletion. Self and Identity, 2(2): 103-117.

Shuqair, S., Pinto, D. C., \& Mattila, A. S. (2019). Benefits of authenticity: Post-failure loyalty in the sharing economy. Annals of Tourism Research, 78: 102741.

Srnicek, N. (2017). Platform capitalism. Cambridge: John Wiley \& Sons.

Stabrowski, F. (2017). 'People as businesses': Airbnb and urban microentrepreneurialism in New York City. Cambridge Journal of Regions, Economy and Society, 10(2): 327-347.

Stergiou, D. P., \& Farmaki, A. (2019). Resident perceptions of the impacts of P2P accommodation: Implications for neighbourhoods. International Journal of Hospitality Management, ahead-of-print.

Strauss, A. \& Corbin, J. (1990). Basics of qualitative research: Grounded theory procedures and techniques. Newbury Park, CA: Sage.

Volgger, M., Taplin, R., \& Pforr, C. (2019). The evolution of 'Airbnb-tourism': Demand-side dynamics around international use of peer-to-peer accommodation in Australia. Annals of Tourism Research, 75: 322-337.

Walker, L. J. (2014). Moral personality, motivation, and identity. In: M. Killen and J. G. Smetana (Eds.), Handbook of Moral Development. New York, NY, US: Psychology Press (pp. 497-519).

Wineberg, T. W. (2006). Enacting an Ethic of Pedagogical Vocation: Pursuing Moral Formation in Responding to the Call of Sacrifice, Membership, Craft, Memory, \& Imagination. Doctoral dissertation, Faculty of Education, Simon Fraser University.

Zhu, Y., Cheng, M., Wang, J., Ma, L., \& Jiang, R. (2019). The construction of home feeling by Airbnb guests in the sharing economy: A semantics perspective. Annals of Tourism Research, 75: 308-321. 